\title{
Biochar Improved Growth of an Important Medicinal Plant (Salvia miltiorrhiza Bunge) and Inhibited its Cadmium Uptake
}

\section{\& Journal of Plant Biology $\&$ Soil Health}

\section{Amei Liu ${ }^{1-4}$, DaikeTian ${ }^{1,2^{*}}$, Yanci Xiang ${ }^{3^{*}}$ and Haibo} Mo $^{1}$

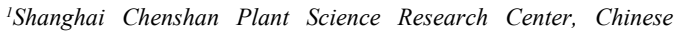
Academy of Sciences, Shanghai, China

${ }^{2}$ Shanghai Key Laboratory for Plant Functional Genomics and Resources, Shanghai Chenshan Botanical Garden, Shanghai, China ${ }^{3}$ School of Life Science, Hunan University of Science and Technology, Xiangtan, Hunan, China

${ }^{4}$ Shanghai Guyi Garden, 218 Huyi Highway, Jiading, Shanghai, China

\section{Keywords: Biochar; Heavy metal pollution; Medicinal plant}

\begin{abstract}
Effects of biochar on the growth of Salvia miltiorrhiza Bunge and heavy metal accumulation in plant tissues were evaluated in artificially Cd-polluted soil. Results showed that plant biomass increased with the proportion (0 to $32 \%$ ) of biochar in the soil mix. However, the impacts of biochar on plant physiological indicators were not clear. Compared with the control, the addition of biochar decreased $\mathrm{Cd}$ content in leaves and roots of $S$. miltiorrhiza by $52.8 \%$ and $43.6 \%$, respectively. Correspondingly, the bioaccumulation coefficient of $\mathrm{Cd}$ was reduced, and the $\mathrm{Cd}$ transfer coefficient decreased with the increase of biochar indicating that biochar inhibited $\mathrm{Cd}$ to transfer from soil to plant. Therefore, biochar has potential for remediation of $\mathrm{Cd}$ or possibly other heavy-metal polluted soils in agricultural crop production.
\end{abstract}

\section{Introduction}

In recent years, with the rapid development of industry and agriculture, a number of heavy metal pollutants were introduced into the soil, water and air through various channels, and moved into agricultural crops and humans, creating significant threats to human health. Research on how to alleviate heavy metal pollution in soil and reduce accumulation of heavy metal in food or medicinal crops has increasingly become an area of great concern [1-4]. Effective remediation of heavy metal pollutants has been widely investigated. Biochar is a new, beneficial ecological restoration material for agricultural production. It can improve the physical and chemical properties of soil, increase microbial activity, reduce nutrient leaching, and enhance nutrient availability, thus contributing to plant growth [5-10]. Biochar also can reduce the bio-availability of pollutants, especially for heavy metals, and is a highly efficient adsorbent $[3,11,12]$. As an environmentally functional material, biochar has drawn increasing attention. Currently, many studies have shown that application of biochar significantly affected the morphology and migration of heavy metals in soil and reduced heavy-metal phytotoxicity $[12,13]$. However, very few cases have been reported on medicinal plants [14]. The major question yet remains unsolved: how much biochar is needed in production practices to make medicinal plants safe for human use when grown in heavy metal polluted soils?

China is a major country for production of herbal medicines. However, the export of its medicinal products is often restricted if its heavy metal concentration exceeds defined limits. Salvia miltiorrhiza Bunge (Danshen in Chinese or red sage or Chinese sage in other areas), as one of the most important traditional Chinese herbs, is

\section{Address for Correspondence}

Daike Tian, Shanghai Chenshan Plant Science Research Center, Chinese Academy of Sciences, Shanghai - 201602, China, Tel/Fax: 86-21-57762652; E-mail: dktian@sibs.ac.cn

Yanci Xiang, School of Life Science, Hunan University of Science and Technology, Xiangtan, Hunan - 411201, China, Tel/Fax: 86-73158291416; E-mail: 2287853008@qq.com

Submission: 27 September, 2016

Accepted: 06 November, 2016

Published: 15 November, 2016

Copyright: ๑ 2016 Liu A, et al. This is an open access article distributed under the Creative Commons Attribution License, which permits unrestricted use, distribution, and reproduction in any medium, provided the original work is properly cited.

widely used in China, Korea, Japan and other Asian countries [15]. Its dried roots contain major active constituents including various kinds of tanshinones that pharmacologically function as treatment for ischemic cardiovascular diseases, microcirculatory disturbancerelated diseases, and coronary disorders $[15,16]$. Cadmium $(\mathrm{Cd})$ has strong chemical activity and potentially high toxicity that creates challenges in remediation. This is significant because $\mathrm{Cd}$ is a major biohazard in China.

A greenhouse experiment was conducted to evaluate effects of biochar on the plant growth and development and its potential for reducing accumulation and toxicity of $\mathrm{Cd}$ on Danshen potted in Cdpolluted soil. This study targets two question:

1. Does biochar affect plant growth and development and Cd uptake in contaminated soil?

2. What is the optimum amount of biochar required in production of Danshen to meet the standard permitted maximum level of $0.3 \mathrm{ppm}$ of $\mathrm{Cd}$ as outlined in herb medicine and set by Chinese Pharmacopoeia (2010).

\section{Material and Methods}

Site details: Plants were potted in a greenhouse located at Shanghai Chenshan Plant Science Research Center ( $31^{\circ} 04^{\prime} 37.18^{\prime \prime N}$; $\left.121^{\circ} 10^{\prime} 35.17^{\prime \prime} \mathrm{E}\right)$, Chinese Academy of Sciences and Chenshan Botanical Garden, China. The average temperature in the greenhouse was $25^{\circ} \mathrm{C}\left(20-36^{\circ} \mathrm{C}\right)$, light intensity $7000 \mathrm{~lx}(2800-9300 \mathrm{~lx})$ during daylight hours, and humidity $60 \%(40-80 \%)$ throughout the experiment between June and September, 2013.

Plant material: Seeds of S. miltiorrhiza were obtained from North West Agriculture and Forestry University, Shanxi, China. They 
Citation: Liu A, Tian D, Xiang Y, Mo H. Biochar Improved Growth of an Important Medicinal Plant (Salvia miltiorrhiza Bunge) and Inhibited its Cadmium Uptake. J Plant Biol Soil Health. 2016;3(2): 6.

ISSN: $2331-8996$

Table 1: Biochar properties.

\begin{tabular}{|c|c|c|c|c|c|}
\hline $\mathbf{p H}$ & $\begin{array}{c}\text { Organic } \\
\text { matter } \\
\mathbf{( c m o l / k g )}\end{array}$ & $\begin{array}{c}\text { Cation } \\
\text { exchange } \\
\text { capacity } \\
\text { (cmol/kg) }\end{array}$ & $\begin{array}{c}\text { Electrical } \\
\text { conductivity } \\
\text { (mS/cm) }\end{array}$ & $\begin{array}{c}\text { Pore } \\
\text { structure } \\
\mathbf{( \% )}\end{array}$ & $\begin{array}{c}\text { Cd content } \\
\text { (mg/kg) }\end{array}$ \\
\hline 9.2 & Immeasurable & 23.2 & 0.69 & $\begin{array}{c}\text { Large 39\%, } \\
\text { small 44\% }\end{array}$ & 0.17 \\
\hline
\end{tabular}

were sown and cultivated in seedling plates in a greenhouse, irrigated regularly with tap water with application of uniform pest control, as needed. Healthy seedlings were selected and transplanted into pots (D: $160 \mathrm{~mm}$; H: $180 \mathrm{~mm}$ ) with soil treatments on June 12, 2013.

Trial design and treatments: Biochar (made from the pinewood) was sieved extracting particles sizes approximately $0.5 \mathrm{~cm}$ to $1.0 \mathrm{~cm}$ in diameter (Table 1). Natural soil (loam) was collected from nearby areas and air-dried followed by removal of rocks, twigs and leaf litter, etc (Table 2).

After recording dry weight, soil was moistened to $40 \%$ maximum field water capacity with deionized water. Sieved biochar was then added and thoroughly mixed with the soil at the ratios: $0 \%$ (CK and $\mathrm{B} 0), 4 \%, 8 \%, 16 \%$ and $32 \%$ char/soil (v/v) and marked as CK, $\mathrm{B} 0, \mathrm{~B} 4, \mathrm{~B} 8, \mathrm{~B} 16, \mathrm{~B} 32$ respectively. One month later, the dissolved $\mathrm{Cd}\left(\mathrm{NO}_{3}\right)_{2} \cdot 4 \mathrm{H}_{2} \mathrm{O}(3 \mathrm{mg} / \mathrm{kg} \mathrm{Cd})$ was added to soil of all treatments other than CK. Seedlings with 3 to 4 leaves were transplanted to the experimental pots with saucers in June, one seedling each pot and 6 pots per treatment. Pots were randomly arranged. Throughout experiment, plants were not fertilized but watered regularly with tap water to maintain soil moisture. To avoid possible leaching of heavy metal and other nutrients, the leachate from the pots was collected and later reapplied to the pots.

\section{Data collection}

Plant growth indicators: Leaf number and area were recorded at $10 \mathrm{~d}, 35 \mathrm{~d}$, and $60 \mathrm{~d}$, respectively, after transplanting. Leaf area was measured by a leaf area meter (YMJ-A Zhejiang Top Instrument Co., Ltd). Both the largest and smallest mature leaves in each pot were measured with the average value taken by calculating leaf area of each treatment (six plants). Eighty days after transplanting, leaves with stems and roots of $S$. miltiorrhiza were harvested separately. After soil removal, root fresh weight was determined before immersing roots in a $0.2 \mu \mathrm{m}$ EDTA solution for $30 \mathrm{~min}$ followed by air-drying for $4 \mathrm{~h}$. Roots were then placed into envelopes and dried at $65^{\circ} \mathrm{C}$ for $48 \mathrm{~h}$ in a drying oven (DHG-9240A, Shanghai Yiheng Instruments Co., Ltd, China). Finally, root dry weight was measured.

Plant physiological indicators: All plant samples were collected with a hole puncher $(1 \mathrm{~cm}$ diameter $)$ at the same position of each fresh leaf. Cell membrane permeability was measured by tissue fluid exosmosis conductance method, using a conductivity meter (DDS$11 \mathrm{AT}$, Shanghai, China) $(\mathrm{n}=3 /$ treatment $)$ to measure water extract of leaves [17].

Relative chlorophyll content of fresh leaves was measured by a handheld chlorophyll meter SPAD-502 plus (Konica Minolta Sensing, Inc, Japan) ( $n=6 /$ treatment), according to Xiong [17].

Methane dicarboxylic aldehyde (MDA) content in fresh leaves was measured by the thiobarbituric acid method $(n=3 /$ treatment by random selection) following Xiong [17].

Superoxide dismutase (SOD) activity was measured by the NBT photochemical reduction method. Enzyme-extracted leaf liquid was collected at the same time as the chromogenic reaction and was measured at $560 \mathrm{~nm}$ OD by an ELISA plate reader (Tecan M200 PRO) ( $\mathrm{n}=3 /$ treatment $)$ [17].

Cd content measurements: $\mathrm{Cd}$ contents in the roots and leaves were determined by Graphite Furnace Atomic Absorption Spectrometry, according to the "Determination of Cadmium in Foods GB/T 5009.15-2003" [18]. Microwave digestion method was carried out with a PE Analyst AA800 (Perkin Elmer) ( $n=3 /$ treatment).

The bioconcentration factor (BCF) reflects the degree or capability of accumulation of heavy metals from soil or water by plants. The biological transfer factor (TF) refers to the transference of heavy metals in plants in vivo [19]. BCF and TF were calculated by:

$\mathrm{BCF}=$ Trace element concentration in plant tissues at harvest/ Initial concentration of the element in the external nutrient solution (1)

$\mathrm{TF}=$ Heavy metal content ratio $(\mathrm{Cd}$ in aboveground tissues $/ \mathrm{Cd}$ in roots) (2)

Table 2: Soil properties.

\begin{tabular}{|c|c|c|c|c|c|c|c|}
\hline $\begin{array}{c}\text { Total nitrogen } \\
(\mathbf{g} / \mathbf{k g})\end{array}$ & $\begin{array}{c}\text { Total phosphorus } \\
(\mathbf{g} / \mathbf{k g})\end{array}$ & $\begin{array}{c}\text { Total potassium } \\
(\mathbf{g} / \mathbf{k g})\end{array}$ & $\mathrm{pH}$ & $\begin{array}{l}\text { Organic matter } \\
\text { (cmol/kg) }\end{array}$ & CEC cmol/k(g) & $\begin{array}{c}\text { Electrical } \\
\text { conductivity (mS/ } \\
\mathbf{c m})\end{array}$ & $\begin{array}{c}\text { Cd content (mg/ } \\
\text { kg) }\end{array}$ \\
\hline 5.44 & 0.65 & 16.4 & 6.08 & 82.46 & 22.79 & 0.33 & 0.38 \\
\hline
\end{tabular}

Table 3: Effects of biochar on leaf growth of S. miltiorrhiza in Cd-polluted soil ( $\bar{x}_{ \pm} s$ ).

\begin{tabular}{|c|c|c|c|c|c|c|}
\hline \multirow{2}{*}{ Biochar rate/\% } & \multicolumn{3}{|c|}{ Leaf number } & \multicolumn{3}{|c|}{ Leaf area $\left(\mathrm{cm}^{2}\right)$} \\
\hline & $10 \mathrm{~d}$ & $35 d$ & $60 \mathrm{~d}$ & $10 \mathrm{~d}$ & $35 \mathrm{~d}$ & $60 \mathrm{~d}$ \\
\hline CK & $19.3 \pm 3.2 b$ & $21.8 \pm 3.2 c$ & $24.3 \pm 4.0 b$ & $37.8 \pm 6.7 a$ & $46.7 \pm 4.00 a b$ & $48.5 \pm 5.6 b c$ \\
\hline B0 & $24.5 \pm 3.1 \mathrm{a}$ & $26.3 \pm 2.9 a b$ & $29.3 \pm 7.3 \mathrm{ab}$ & $31.5 \pm 4.3 a$ & $39.8 \pm 3.7 b c$ & $41.3 \pm 4.0 \mathrm{c}$ \\
\hline B4 & $21.0 \pm 1.6 \mathrm{ab}$ & $23.5 \pm 2.9 \mathrm{bc}$ & $26.5 \pm 3.4 b$ & $32.2 \pm 4.8 \mathrm{a}$ & $38.6 \pm 5.2 c$ & $43.9 \pm 6.4 \mathrm{bc}$ \\
\hline B8 & $23.5 \pm 1.0 \mathrm{a}$ & $27.5 \pm 2.1 \mathrm{a}$ & $30.8 \pm 2.2 a b$ & $33.9 \pm 2.7 \mathrm{a}$ & $38.8 \pm 7.2 \mathrm{c}$ & $51.2 \pm 4.5 \mathrm{ab}$ \\
\hline B16 & $24.5 \pm 1.9 a$ & $30.0 \pm 2.5 a$ & $33.8 \pm 1.5 a$ & $35.1 \pm 4.2 \mathrm{a}$ & $45.8 \pm 4.2 b c$ & $60.0 \pm 3.8 \mathrm{a}$ \\
\hline B32 & $24.5 \pm 1.0 \mathrm{a}$ & $29.3 \pm 1.0 \mathrm{a}$ & $35.0 \pm 2.7 a$ & $34.3 \pm 4.5 a$ & $52.0 \pm 1.2 \mathrm{a}$ & $58.1 \pm 4.1 \mathrm{a}$ \\
\hline
\end{tabular}

CK indicates no biochar and no Cd in the soil; B0, B4, B8, B16, and B32 indicate adding $0 \%, 4 \%, 8 \%, 16 \%$, and $32 \%$ of biochar in soil, respectively; Different lower case letters in the same column indicate significant differences $(P<0.05)$ among treatments. 
Citation: Liu A, Tian D, Xiang Y, Mo H. Biochar Improved Growth of an Important Medicinal Plant (Salvia miltiorrhiza Bunge) and Inhibited its Cadmium Uptake. J Plant Biol Soil Health. 2016;3(2): 6.

ISSN: 2331-8996

Table 4: Effects of biochar on relative chlorophyll content of S. miltiorrhiza in Cd-polluted soil.

\begin{tabular}{|l|l|l|l|}
\hline \multirow{2}{*}{ Biochar rate } & \multicolumn{3}{|c|}{ Relative chlorophyll content } \\
\cline { 2 - 4 } & $\mathbf{1 0 ~ d}$ & $\mathbf{3 5 ~ d}$ & \multicolumn{1}{c|}{$\mathbf{6 0 ~ d}$} \\
\hline CK & $16.9 \pm 0.2 \mathrm{a}$ & $22.1 \pm 0.4 \mathrm{a}$ & $14.5 \pm 0.4 \mathrm{ab}$ \\
\hline B0 & $16.6 \pm 0.8 \mathrm{ab}$ & $22.5 \pm 0.8 \mathrm{a}$ & $13.0 \pm 0.5 \mathrm{ab}$ \\
\hline B4 & $16.0 \pm 1.55 \mathrm{~b}$ & $22.1 \pm 0.7 \mathrm{a}$ & $12.4 \pm 0.9 \mathrm{bc}$ \\
\hline B8 & $16.5 \pm 0.8 \mathrm{ab}$ & $22.9 \pm 1.2 \mathrm{a}$ & $12.0 \pm 0.9 \mathrm{C}$ \\
\hline B16 & $16.2 \pm 0.5 \mathrm{ab}$ & $22.3 \pm 1.3 \mathrm{a}$ & $12.3 \pm 0.9 \mathrm{bc}$ \\
\hline B32 & $16.2 \pm 0.5 \mathrm{ab}$ & $23.0 \pm 0.6 \mathrm{a}$ & $13.6 \pm 0.4 \mathrm{a}$ \\
\hline
\end{tabular}

CK indicates no biochar and no Cd in soil; B0, B4, B8, B16, and B32 indicate adding $0 \%, 4 \%, 8 \%, 16 \%$, and $32 \%$ of biochar in soil, respectively; Different lower case letters in the same column indicate significant differences $(P<0.05)$ among treatments.

\section{Statistical analysis}

Microsoft Excel 2007 was used to calculate averages, and Statistical Package for Social Scientists (SPSS 16.0) was used to calculate the analysis of variance (ANOVA), Duncan's Multiple Range Test, the standard deviation, and regression analysis. Significance level was set at $\alpha=0.05$.

\section{Results}

Effects of biochar on the growth of S. miltiorrhiza in Cd-polluted soil

Leaf growth: No apparent leaf toxicity was morphologically observed $10 \mathrm{~d}$ after adding $\mathrm{Cd}$ and biochar treatments, but both leaf number and area of plants in treated soil increased $35 \mathrm{~d}$ after being treated and later with both of these values reaching the highest levels in the treatments with the highest biochar proportion (B32) in the final measurement at $60 \mathrm{~d}$ (Table 3). At $60 \mathrm{~d}$, the leaf number of B4, B8, B16 and B32 increased 26.2\%, 30.9\%, 37.8\%, and $42.9 \%$, respectively, while that of CK and B0 increased $19.4 \%$ and $26.0 \%$, respectively, compared with those at $10 \mathrm{~d}$. Likewise, leaf area of B4, B8, B16 and B32 increased 36.3\%, 50.9\%, 70.7\%, and 69.9\%, respectively, while that of CK and B0 just increased $28.3 \%$ and $31.0 \%$, respectively. Therefore, the leaf number and area increased with amount of added biochar, and leaf growth was significantly promoted with the addition of $16 \%$ to $32 \%$ biochar (with Cd added). Higher ratios of biochar promoted more leaf growth but also increased cost (biochar cost). Lower concentrations of $\mathrm{Cd}$ did not cause strong toxicity problems, but resulted in the smaller leaf size and slower growth of plants.

Plant biomass: Biomass discrepancy is the most direct response of plants to various environmental stimuli. Total fresh weight, leaf fresh weight, and the fresh and dry weight of roots increased with the addition of biochar in our study (Figure 1). All the highest values of the tested plant growth indices occurred in treatment B32 where the highest total fresh weight was 1.3 times of that in treatment B0. The fresh weight of roots made a greater contribution to the total fresh weight than that of the leaves and stems, and it correlated significantly with the biochar proportion. The maximum root fresh and dry weight observed in B32 was 1.4 times of that in the control, which further verified that biochar promoted root growth.

\section{Effects of biochar on physiological characteristics}

Relative chlorophyll content: The relative content of chlorophyll in living leaves measured by SPAD can be used to evaluate plant growth, physiological changes and nitrogen nutrition. Three consecutive measurements of relative chlorophyll content were carried out at $10 \mathrm{~d}, 35 \mathrm{~d}$, and $60 \mathrm{~d}$, respectively, after transplanting (Table 4). Relative chlorophyll contents in the leaves of treated plants were higher than those in the control, but no difference was found between the treatments of biochar ratios. The highest chlorophyll content in all treatments occurred at $35 \mathrm{~d}$ when the leaves were at the peak stage of growth. The highest increase rate of chlorophyll content from $10 \mathrm{~d}$ to $35 \mathrm{~d}$ was in treatment B32 (42\%), indicating that Cd might affect the enzyme activity relevant to chlorophyll synthesis, and it stimulated the chlorophyll formation at a certain concentration. Sixty days after biochar treatment, the relative chlorophyll content began to decrease slowly as the plants gradually senesced.

Cell membrane permeability: Maximum cell membrane conductivity occurred in treatment $\mathrm{B} 0$ and it was significantly higher than that in both the control $(\mathrm{CK})$ and biochar treatments (Figure 2a). This demonstrated that $3 \mathrm{mg} / \mathrm{kg}$ of Cd caused plant stress with increased membrane permeability. Data showed that adding biochar could reduce cell membrane conductivity, but the reducing effect was not proportional to the biochar ratio. Similar cell membrane conductivity was found between the biochar treatments and the CK.

MDA content: Figure $2 b$ showed the effects of biochar on MDA content of plants grown for $30 \mathrm{~d}$ in Cd-polluted soil. The highest MDA content was seen in CK, which indicated that the amount of $\mathrm{Cd}$ did produce some impact on the lipid peroxidation of cell membranes. Less MDA content occurred in biochar treatments and the lowest was seen in B16, although no differences were found among the treatments with both $\mathrm{Cd}$ and biochar. The possible reason for no difference in treatments might be that the physiological metabolic activity was disturbed by the MDA accumulation due to $\mathrm{Cd}$ addition, while the MDA accumulation was inhibited by biochar, which alleviated the damage of the membrane system caused by lipid membrane peroxidation.

SOD activity: When plants grew for $30 \mathrm{~d}$ in Cd-contaminated soil, the effects of biochar on SOD activity in fresh leaves reached a

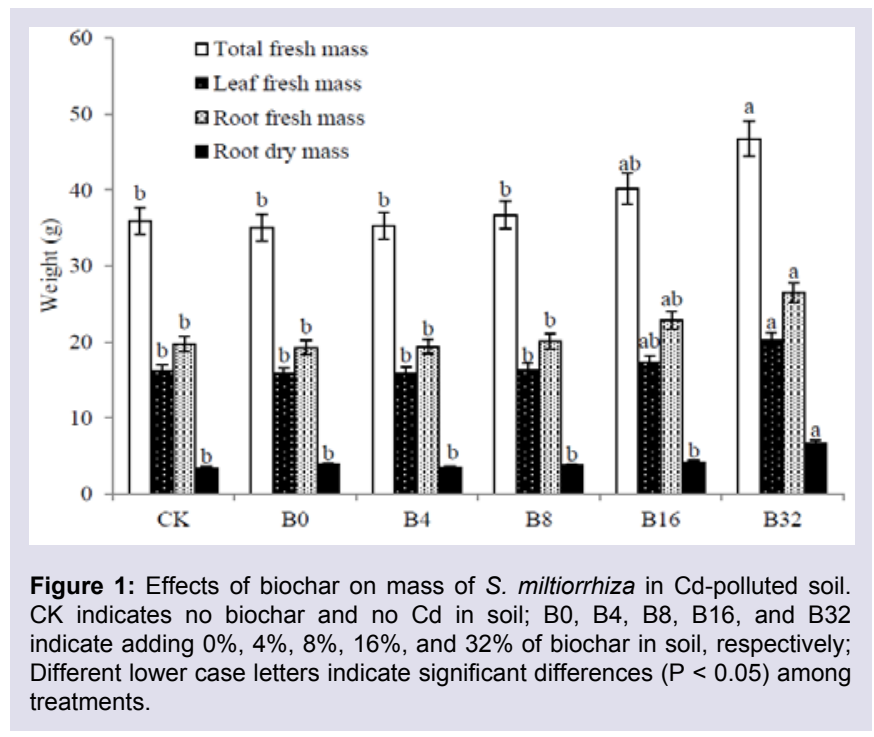


Citation: Liu A, Tian D, Xiang Y, Mo H. Biochar Improved Growth of an Important Medicinal Plant (Salvia miltiorrhiza Bunge) and Inhibited its Cadmium Uptake. J Plant Biol Soil Health. 2016;3(2): 6.
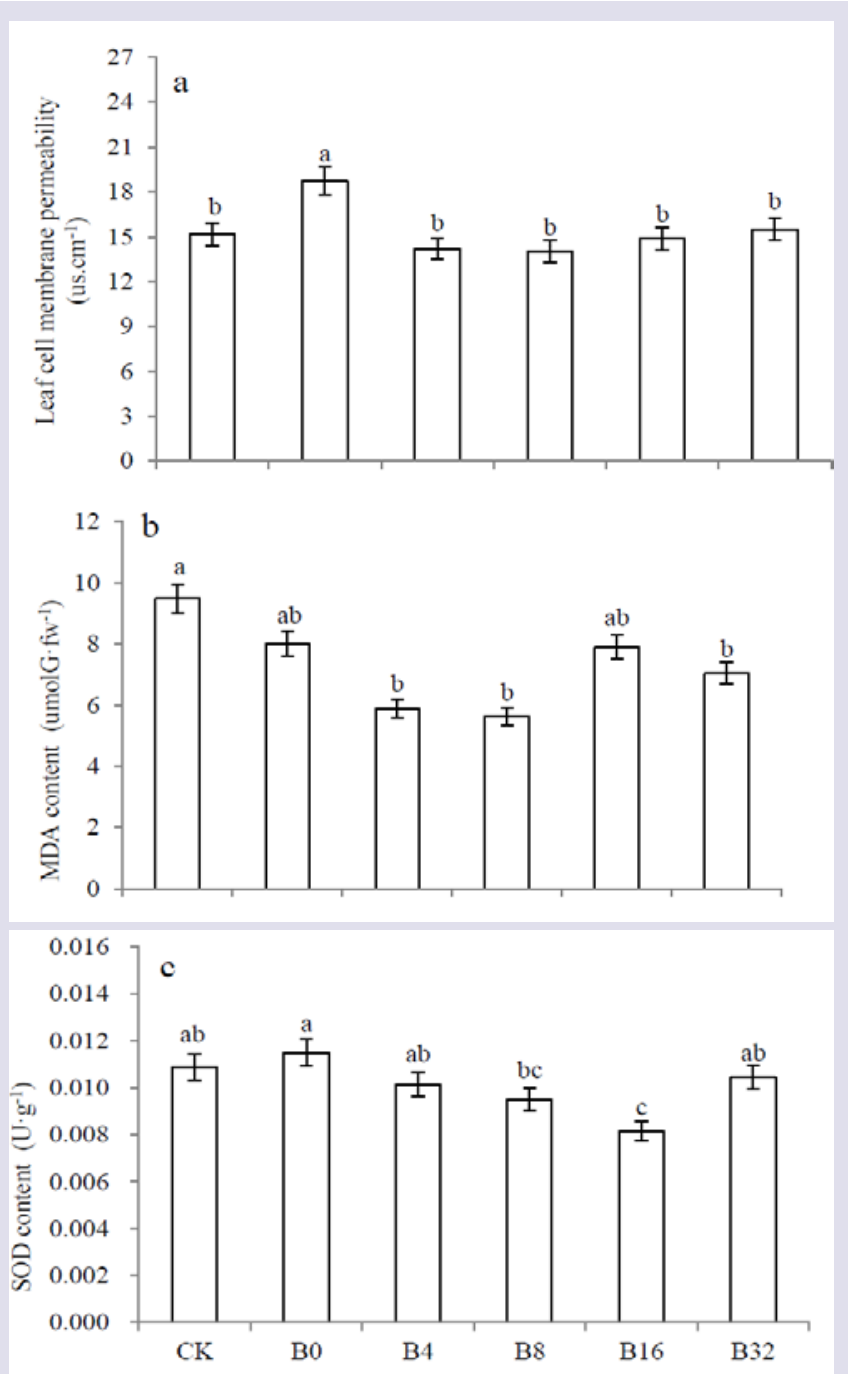

Figure 2: Effects of biochar on leaf cell membrane permeability, MDA content, SOD activity of $S$. miltiorrhiza in Cd-polluted soil.

CK indicates no biochar and no Cd in soil; B0, B4, B8, B16, and B32 indicate adding $0 \%, 4 \%, 8 \%, 16 \%$, and $32 \%$ of biochar in soil, respectively; Different lower case letters indicate significant differences $(P<0.05)$ among treatments.

significant level (Figure 2c). The highest SOD activity appeared in treatment $\mathrm{B} 0$, which indicated that $3 \mathrm{mg} / \mathrm{kg} \mathrm{Cd}$ in soil significantly enhanced the SOD activity of S. miltiorrhiza. However, after adding biochar, SOD activity declined, with the highest decrease (29\%) in treatment B16, compared to the control, B0, although the decreasing trend was inconsistent with the proportion of biochar.

\section{Cd content}

After adding $\mathrm{Cd}$, the $\mathrm{Cd}$ accumulation in plants clearly increased (Figure 3). In treatment B0, Cd content in roots and leaves was 0.57 $\mathrm{mg} / \mathrm{kg}$ and $0.18 \mathrm{mg} / \mathrm{kg}$, respectively, increased to 2.2 and 2.0 folds compared with the control. However, with increasing biochar, Cd content in roots and leaves decreased correspondingly. Cd content in roots of B32 was the lowest $0.25 \mathrm{mg} / \mathrm{kg}$, only $43.6 \%$ of that in B0; Cd content in leaves of B32 reduced much more, down to $0.09 \mathrm{mg} / \mathrm{kg}$, a decrease of $52.8 \%$ of the highest in B0. Cd content in S. miltiorrhiza was below the upper limit value set by "Chinese Pharmacopoeia" (2010).

The regression equations for the proportion of biochar $(\mathrm{x})$ related to $\mathrm{Cd}$ content in roots $(\mathrm{y})$ and leaves $(\mathrm{y})$ were:

$$
\begin{aligned}
& y=-0.00007 x^{3}+0.003 x^{2}-0.046 x+0.067\left(R^{2}=0.997, P=0.067\right) \\
& y=-0.00007 x^{3}+0.002 x^{2}-0.023 x+0.177\left(R^{2}=0.991, P=0.119\right)(4)
\end{aligned}
$$

Data showed that the increasing proportion of biochar in $3 \mathrm{mg} / \mathrm{kg}$ $\mathrm{Cd}$-contaminated planting medium was likely to further reduce $\mathrm{Cd}$ content and help the roots (a major medicinally used part) meet safe standards of Chinese medicine.

Cd BCF and TF: The BCF shows the capacity of plants to adsorb heavy metals. In our study, the highest BCF $(0.19)$ of the roots was observed in B0, 2.2 times that of the control, indicating that roots had the ability to accumulate $\mathrm{Cd}$ (Figure 4 ). But, after adding biochar, the $\mathrm{BCF}$ of both root and leaf decreased with the rate of biochar. The lowest root $\mathrm{BCF}(0.08)$ occurred in treatment $\mathrm{B} 32$ was lower than the control and only $43 \%$ of the highest observed in B0. Likewise, the lowest leaf BCF was also seen in B32, 77.5\% of the highest in B0. It is possibly due to the capacity of biochar to inhibit absorption of $\mathrm{Cd}$ in plants.

The transfer factor from roots to leaves (TF) showed Cd can be absorbed from soil by $S$. miltiorrhiza and transported among different plant organs. The highest TF was observed in the control (0.65). TF decreased with the addition of $\mathrm{Cd}$. This could be explained by $\mathrm{Cd}$ potentially inhibiting growth and metabolism of S. miltiorrhiza, therefore slowing the absorbed Cd from the roots. With the increasing biochar proportion, TF decreased correspondingly. The lowest TF was 0.3 in B32, less than half of that in the control, indicating that biochar could affect the transfer of $\mathrm{Cd}$ from roots to leaves.

\section{Discussion}

\section{Effects of biochar on plant growth}

In this study, $3 \mathrm{mg} / \mathrm{kg} \mathrm{Cd}$ added to the soil-biochar mix did not cause obvious morphological symptoms of heavy metal toxicity, but resulted in treated plants being stunted and undersized when compared to CK and biochar treatments. Leaf growth, total fresh



Figure 3: Effects of biochar on Cd content in root and leaf of S. miltiorrhiza in Cd-polluted soil.

CK indicates no biochar and no Cd in soil; B0, B4, B8, B16, and B32 indicate adding $0 \%, 4 \%, 8 \%, 16 \%$, and $32 \%$ of biochar in soil, respectively; Different lower case letters indicate significant differences $(P<0.05)$ among treatments. 


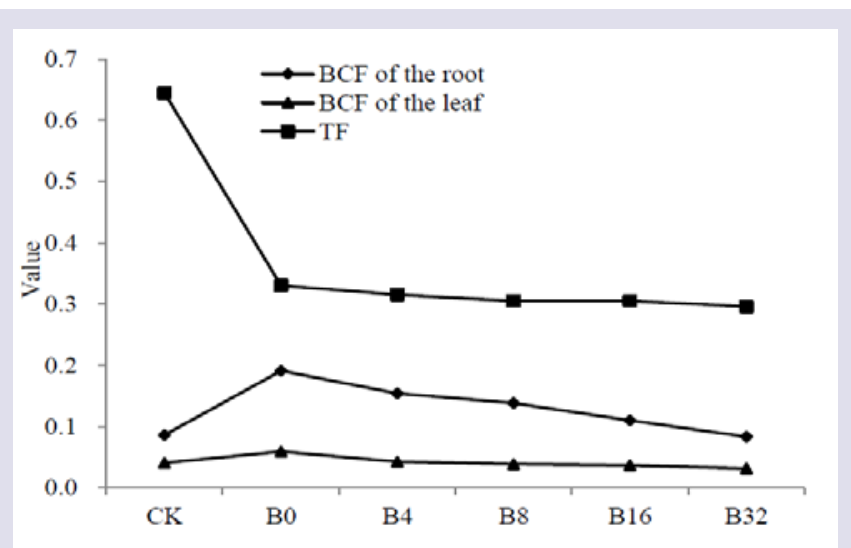

Figure 4: Effects of biochar on Cd bioconcentration factor (BCF) and biological transfer factor (TF) of S. miltiorrhiza in Cd-polluted soil.

CK indicates no biochar and no Cd in soil; B0, B4, B8, B16, and B32 indicate adding $0 \%, 4 \%, 8 \%, 16 \%$, and $32 \%$ of biochar in soil, respectively.

weight, fresh and dry root weight of S. miltiorrhiza increased with biochar proportion, and nearly all the highest values appeared in the treatment with the largest amount of biochar. Therefore, biochar can promote plant growth, as is reported in the previous studies $[8,20]$. Because no fertilizer was applied after adding biochar, the biomass increase suggests that biochar might work as a fertilizer enhancer, or affects soil nutrient availability, such as the effectiveness of $\mathrm{K}, \mathrm{Ca}$, $\mathrm{Na}, \mathrm{Mg}, \mathrm{N}, \mathrm{P}$, or increase the rhizosphere and soil nitrogen retention indirectly [20-22]. Although Cd inhibited plant growth, adding biochar offset the Cd stress and promoted biomass increase. Adding $16 \%$ to $32 \%$ of biochar in soil was more beneficial in our study. Yet some studies also showed that biochar had no beneficial effect on plant growth, which related to the type of soil and biochar, fertility levels and other relevant experimental conditions $[6,23,24]$.

\section{Effects of biochar on physiological indices}

Cell membrane permeability, relative chlorophyll content, MDA and SOD serve as markers to represent plant reactions under stress conditions in our experiment. Cd added in the soil produced a heavy metal stress on the cell membrane structure, but no difference resulted from treatments with different proportions of biochar. Therefore, there was no the optimal biochar level established in this study based on this point. Beneficial effects of biochar on membrane permeability were possibly affected by other environmental factors, such as $\mathrm{pH}$, EC, etc., making the membrane permeability change irregularly. Leaf chlorophyll content increased with increasing biochar in all treatments, which coincided with the results of other previous studies, in which low Cd concentration facilitated chlorophyll formation and high Cd concentration reduced chlorophyll content [25]. This phenomenon also occurred in other heavy metal study cases [26]. Earlier research showed no evident promotion effect of biochar on chlorophyll levels, but an obvious increase of chlorophyll occurred in the mid-term growth stage, and a relatively large decrease in the later period. This might be the result of adding biochar, which promoted plant growth but advanced plant senescence simultaneously. The significant differences showed in MDA content between treatments with and without biochar, indicated that biochar alleviated the cell membrane peroxidation caused by $\mathrm{Cd}$. SOD activity increased with $\mathrm{Cd}$, showing that $\mathrm{Cd}$ stimulated the physiological defense mechanisms and physiological resistance activities, improved antioxidant enzyme activity and antioxidant activity [27]. However, the addition of biochar caused a decrease of SOD activity, which suggests that biochar could ameliorate Cd hazards.

\section{Effects of biochar on Cd content in plants}

Cd easily accumulates in roots and aboveground plant tissue of $S$. miltiorrhiza, but the addition of biochar decreased Cd concentrations in plant organs in our experiment. Cd content in roots was reduced and could meet the maximum allowed value set by "Chinese Pharmacopoeia" (2010). The maximum biochar suppressive uptake effect was observed in B32. Cd content in plants could possibly be further decreased with more biochar added, extrapolating from the regression equation of biochar and $\mathrm{Cd}$ content. The role of biochar on reducing the heavy metal accumulation in plants has been demonstrated in the previous reports $[4,28]$. It might be related to huge specific surface area and strong adsorption functions of biochar to form insoluble chelates or cause precipitation of Cd. BCFs of root and leaf decreased with the addition of biochar indicates, besides its strong ability of adsorbing $\mathrm{Cd}$, biochar also reduces the bioavailability of heavy metals, or immobilizes heavy metals by changing the physicochemical property of soil [29]. The highest TF value showed in $\mathrm{B} 0$, and the lowest in B32, which indicates that biochar inhibits mobility of Cd. Based on the values of Cd content, BCF and TF, 32\% biochar was the optimum amount applied for better plant growth promotion, fertilizer efficiency and heavy-metal pollutant reduction.

\section{Conclusions}

In this study, effects of biochar were evaluated on S. miltiorrhiza, an important medicinal plant. Results showed that biochar not only promoted plant growth but also alleviated toxic effects of $\mathrm{Cd}$ in $\mathrm{Cd}$ contaminated soil. Contents of $\mathrm{Cd}$ in roots, leaves and stems of $S$. miltiorrhiza were significantly reduced and the transference of $\mathrm{Cd}$ in plants was inhibited by adding biochar. Further studies are needed to evaluate effects of biochar on safe production of other Chinese medicinal plants and to establish the optimum physiologically and economically feasible amount of biochar to add under heavy-metal polluted conditions.

\section{References}

1. Kurz H, Schulz R, Römheld V (1999) Selection of cultivars to reduce the concentration of cadmium and thallium in food and fodder plants. J Plant Nutr Soil Sci 162: 323-328.

2. Martinsen V, Mulder J, Shitumbanuma V, Sparrevik M, Børresen T, et al. (2014) Farmer-led maize biochar trials: effect on crop yield and soil nutrients under conservation farming. J Plant Nutr Soil Sci 177: 681-695.

3. Lu H, Li Z, Fu S, Méndez A, Gascó G, et al. (2015) Effect of biochar in cadmium availability and soil biological activity in an Anthrosol following acid rain deposition and aging. Water Air Soil Pollut 226: 164-174.

4. Puga AP, Abreu CA, Melo LC, Paz-Ferreiro J, Beesley L (2015) Cadmium, lead, and zinc mobility and plant uptake in a mine soil amended with sugarcane straw biochar. Environ Sci Pollut Res Int 22: 17606-17614.

5. Ventura F, Salvatorelli F, Piana S, Pieri L, Pisa PR (2012) The effects of biochar on the physical properties of bare soil. Earth Environ Sci Trans R Soc Edinb 103: 5-11.

6. Alburquerque JA, Salazar P, Barrón V, Torrent J, del Campillo MC, et al (2013) Enhanced wheat yield by biochar addition under different mineral fertilization levels. Agron Sustain Dev 33: 475-484. 
Citation: Liu A, Tian D, Xiang Y, Mo H. Biochar Improved Growth of an Important Medicinal Plant (Salvia miltiorrhiza Bunge) and Inhibited its Cadmium Uptake. J Plant Biol Soil Health. 2016;3(2): 6.

7. Steinbeiss S, Gleixner G, Antonietti M (2009) Effect of biochar amendment on soil carbon balance and soil microbial activity. Soil Biol Biochem 41: 1301 1310.

8. Huang M, Yang L, Qin H, Jiang L, Zou Y (2014) Fertilizer nitrogen uptake by rice increased by biochar application. Biol Fertil Soils 50: 997-1000.

9. Sika MP, Hardie AG (2014) Effect of pine wood biochar on ammonium nitrate leaching and availability in a South African sandy soil. Eur J Soil Sci 65: 113 119

10. Reverchon F, Flicker RC, Yong H, Yan G, Xu Z, et al. (2014) Changes in $\delta^{15} \mathrm{~N}$ in a soil-plant system under different biochar feedstocks and application rates. Biol Fertil Soils 50: 275-283.

11. Lohmann R, Macfarlane JK, Gschwend PM (2005) Importance of black carbon to sorption of native PAHs, PCBs, and PCDDs in Boston and New York harbor sediments. Environ Sci Technol 39: 141-148.

12. Beesley L, Moreno-Jiménez E, Gomez-Eyles JL (2010) Effects of biochar and greenwaste compost amendments on mobility, bioavailability and toxicity of inorganic and organic contaminants in a multi-element polluted soil. Environ Pollut 158: 2282-2287.

13. Uchimiya M, Lima IM, Thomas Klasson K, Chang S, Wartelle LH, et al. (2010) Immobilization of heavy metal ions (Cull, Cdll, Nill, and PbII) by broiler litterderived biochars in water and soil. J Agric Food Chem 58: 5538-5544.

14. Jeffery S, Verheijen FG, van der Velde M, Bastos AC (2011) A quantitative review of the effects of biochar application to soils on crop productivity using meta-analysis. Agr Ecosyst Environ 144: 175-187.

15. Han JY, Fan JY, Horie Y, Miura S, Cui DH, et al. (2008) Ameliorating effects of compounds derived from Salvia miltiorrhiza root extract on microcirculatory disturbance and target organ injury by ischemia and reperfusion. Pharmaco Ther 117: 280-295.

16. Pan X, Niu G, Liu H (2001) Microwave-assisted extraction of tanshinones from Salvia miltiorrhiza bunge with analysis by high-performance liquid chromatography. J Chromatogr 922: 371-375.

17. Xiong QE (2003) Plant physiology experiments tutorial. 1st edition. Chengdu China, Sichuan Science and Technology Press, pp. 124-127.

18. Ministry Health China (2003) GB/T 5009.15-2003 Determination of cadmium in Foods. Standardization Administration of China.
19. Zayed A, Gowthaman S, Terry N (1998) Phytoaccumulation of trace elements by wetlands plants: I. Duckweed. J Environ Qual 27: 715-721.

20. Utomo WW, Guritno B, Soehoo LA (2012) The effect of biochar on the growth and $\mathrm{N}$ fertilizer requirement of maize (Zea mays $\mathrm{L}$.) in green house experiment. J Agric Sci 4: 255-262.

21. Oguntunde PG, Fosu M, Ajayi AE, van de Gesen N (2004) Effects of charcoal production on maize yield, chemical properties and texture of soil. Biol Fertil Soils 39: 295-299.

22. Prendergast-Miller MT, Duvall M, Sohil SP (2014) Biochar-root interactions are mediated by biochar nutrient content and impacts on soil nutrient availability. Eur J Soil Sci 65: 173-185.

23. Devereux RC, Sturrock CJ, Mooney SJ (2012) The effects of biochar on soil physical properties and winter wheat growth. Earth Environ Sci Trans R Soc Edinb 103: 13-18.

24. Eyles A, Bound SA, Oliver G, Corkrey R, Hardie M, et al. (2015) Impact of biochar amendment on the growth, physiology and fruit of a young commercial apple orchard. Trees 29: 1817-1826.

25. Shenchang Y, Qi W (2003) Effect of Cd on growth and physiological characteristics of Aegiceras conrniculatum seedlings. Mar Environ Sci 22: 38-42.

26. Jonker MT, Koelmans AA (2002) Sorption of polycyclic aromatic hydrocarbons and polychlorinated biphenyls to soot and soot-like materials in the aqueous environment: mechanistic considerations. Environ Sci Technol 36: 37253734.

27. Zheng-Zheng L, Jun $\mathrm{W}$, Ya T, Gang $\mathrm{Y}$ (2007) Effect of $\mathrm{Pb}, \mathrm{Zn}$ and their interactions on the chlorophyll content and antioxidant enzyme systems of Houttuynia cordata Thunb. Ecol 27: 5441-5446.

28. Fellet G, Marchiol L, Delle Vedove G, Peressotti A (2011) Application of biochar on mine tailings: effects and perspectives for land reclamation. Chemosphere 83: 1262-1267.

29. Rees F, Simonnot MO, Morel JL (2014) Short-term effects of biochar on soil heavy metal mobility are controlled by intra-particle diffusion and soil $\mathrm{pH}$ increase. Eur J Soil Sci 65: 149-161.

\section{Acknowledgement}

This study is supported by the funding from Shanghai Administration Bureau of Landscape and City Appearance (Fund code: F112421), the Natural Science Foundation of Hunan Province (No. 2015JJ2065), and the Projects of Hunan Environmental Protection (No. 2012[347], No. 2013[229]). Special thanks go to Dr. Ken Tilt for help on editing the text and Dr. Yukun Wei for providing with S.miltiorrhiza seeds. 